\title{
Impact Genetic Characterization of H5N1 Avian Influenza Virus Isolated from Dead Mute Swan (Cygnus Olor)
}

\author{
Bogoyavlenskiy Andrey ${ }^{1}$, Korotetskiy llya $^{1}$, Turmagambetova Aizhan ${ }^{1}$, \\ Prilipov Alexey ${ }^{2}$, Abitayeva Madina ${ }^{1}$, Soldatova Irina $^{1}$ and Berezin Vladimir $^{1}$ \\ ${ }^{1}$ Institute of Microbiology and Virology, Almaty, Kazakhstan \\ ${ }^{2}$ D.I. Ivanovsky Institute of Virology, Moscow, Russia
}

\begin{abstract}
Background and aim: The influenza viruses pose a threat of emergence of a global pandemic influenza through point mutation or reassortment, leading to a strain that can effectively transmit among humans. In this study, the authors present phylogenetic and genetic evidences for the interlineage reassortment among avian influenza viruses isolated in Kazakhstan in 2006 from a mute swan.

Methods: This study demonstrates the dynamic nature of the influenza virus genes pool in Eurasia with continuing gene exchanges between the eastern and western parts of the continent. Results: The findings suggest that the H5N1 - like virus were likely derived directly from viruses resident in migratory birds. Conclusion: The failure to identify the source of all gene segments of $\mathrm{A} /$ mute swan/Aktau/1460/06 virus and its variant highlights the need of continued and extensive surveillance in both migratory and domestic populations of birds in large regions. Such surveillance is crucial for efficient pandemic influenza preparedness.
\end{abstract}

Keywords: Mute swan, avian influenza, phylogenetic characterization, nature reassortant.

\section{Introduction}

In addition to antigenic drift (Alexander, 2007; Cox, 2000; Horimoto, 2005), caused by errors in viral replication and the antigenic pressure applied to the surface hemagglutinin and neuraminidase antigens by the immune response, the evolution of influenza virus is shaped by the reassortment process (Kaverin, 2010; Webster, 2004). Influenza virus has a high potential to reassort due to the segmented nature of its genome that consists of eight negative-strand RNA segments. When two different strains of influenza virus coinfect the same cell, progeny viruses (reassortants) are created that contain genes derived from each parent. Genetic reassortment among influenza viruses occurs naturally and plays the important role in viral epidemiology and pathogenicity (Horimoto, 2001).

At least two of the major Influenza pandemics of the 20th century, H2N2 in 1957 and H3N2 in 1968, resulted from reassortments between viruses from two different hosts; avian and human (Forrest, 2010). The reassortment event in 1998 gave rise to the triple reassortant, which is the ancestor of the 2009 pandemic virus (Horimoto, 2001; Forrest, 2010). Subsequent reassortment with H1N1 swine strain resulted in generation of triple reassorted swine A (H1N1) virus that caused the 2009 H1N1 influenza pandemic (Horimoto, 2001; Forrest, 2010). Therefore, study of natural reassortants of

Copyright (C) 2012 Bogoyavlenskiy Andrey, Korotetskiy Ilya, Turmagambetova Aizhan, Prilipov Alexey, Abitayeva Madina, Soldatova Irina and Berezin Vladimir. This is an open access article distributed under the Creative Commons Attribution License unported 3.0, which permits unrestricted use, distribution, and reproduction in any medium, provided that original work is properly cited. Contact author: Bogoyavlenskiy Andrey E-mail: anpav_63@mail.ru 
the influenza virus is important for epidemiology, diagnosis and vaccination of this infection.

Since late 2005, highly pathogenic avian influenza (HPAI) viruses of H5N1 subtype have spread into Europe, the Middle East and Africa affecting both wild birds and poultry (Lei, 2011). Three distinct sublineages were identified in these regions, termed EMA1 (2.2.1), EMA2 (2.2.2) and EMA3 (2.2.3) by Salzberg et al. (2007) (Salzberg, 2007). Incursions into the European Union have been seen mainly in the wild birds, and the limited outbreaks occurring in poultry, as a result of the spread from wild birds or from poultry to other domestic birds, have been promptly eradicated in the vast majority of the European countries. In contrast, in Africa and in the Middle East, since the first outbreaks reported in early 2006 , there has been extensive spreading and circulation of H5N1 virus in poultry, except only an extremely limited number of isolations from wild birds (Horimoto, 2001; Webster, 2004). It is still unclear how H5N1 virus reached these two regions, whether through wild bird movements, trade of infected poultry commodities or both.

The first report of highly pathogenic avian influenza A (H5N1) virus in Kazakhstan was reported for the first time in July 2005 in Pavlodar region (North-East Kazakhstan), and then it was isolated in Akmolinsk region (Central Kazakhstan), North Kazakhstan region and Karaganda region (Central Kazakhstan). In March 21, 2006, a dead wild swan was found in Mangystau region (South-West Kazakhstan) on Caspian Sea coast. Assay of the pathology finding from this bird suggested avian influenza infection of A/H5N1 type. 70 wild birds have died from H5N1 epizooty in this region in total (Tabynov, 2008; Kydyrbaev, 2010). The phylogenetic analysis has shown that the virus which has been registered in Mangystau region was different from EMA groups of HPAI H5N1 viruses and had NS2A genotype that was typical for Gs/Gdlike strains (Chervyakova, 2011; Bogoyavlenskiy, 2011). The study of biological properties has shown that the virus had high pathogenic properties (Sayatov, 2007).

This study is focused on the molecular and phylogenetic analysis of H5N1 virus isolated in Mangystau region of Kazakhstan.

\section{Methods}

\section{Virus Isolation and Characterization}

Virus was isolated from dead mute swan found on Caspean Sea coast and characterized in the laboratory of ecology of viruses of the Institute of microbiology and virology, Almaty, Kazakhstan and in the Institute for Biological Safety Problems, Ste Gvardeiskiy, Zhambyl Region, Kazakhstan. To isolate the virus, the samples of bird visceral organs were mixed with an equal volume of phosphate buffered saline containing antibiotics (penicillin $2000 \mathrm{U} / \mathrm{ml}$, streptomycin 2 $\mathrm{mg} / \mathrm{ml}$ and gentamicin $50 \mu \mathrm{g} / \mathrm{ml}$ ), incubated for 20 minutes in room temperature, and centrifuged at $1,500 \times \mathrm{g}$ for $15 \mathrm{~min}$. The supernatant $(0.2 \mathrm{ml} / \mathrm{egg})$ was inoculated into the allantoic route of 9day-old hen embryonated eggs as described in European Union Council Directive 92/40/EEC [15]. Embryonic death within the first 24 hours of incubation was considered non-specific and these eggs were discarded. After incubation at $37^{\circ} \mathrm{C}$ for $72 \mathrm{~h}$, the allantoic fluid was collected and tested by haemagglutination (HA) assay as described in European Union Council Directive 92/40/EEC. In the cases where no influenza A virus was detected during initial virus isolation attempt, the allantoic fluid was passaged twice in 9-day-old hen embryonated eggs. The number of virus passages in hen embryonated eggs was limited to the maximum two, to limit laboratory manipulation. A sample was considered negative when the second passage HA test was negative. The subtypes of the virus isolates were determined by conventional haemagglutination inhibition (HI) test and neuraminidase inhibition (NI) test, as described in European Union Council Directive 92/40/EEC. 


\section{RNA Extraction and PCR}

RNA was extracted from infective allantoic fluid using RNeasy Mini Kit (QIAGENE, $\mathrm{GmbH}$, Germany) accordingly to the manufacturer's instructions. RNA was converted to full-length cDNA using reverse transcriptase. The RT mix comprised $2.5 \mu \mathrm{l}$ of DMPC water, $5 \mu \mathrm{l}$ of $5 \times$ First Strand buffer (Invitrogen), $0.5 \mu$ l of 10 mM dNTP mix (Amersham Biosciences), 2 $\mu \mathrm{l}$ of $50 \mathrm{mM}$ UNi12 primer, $32 \mathrm{U}$ of RNAguard (Amersham Biosciences), $200 \mathrm{U}$ of MMLV reverse transcriptase (Invitrogen) and $5 \mu$ RNA solution in total volume of 25 $\mu \mathrm{l}$. The reactions were incubated at $42^{\circ} \mathrm{C}$ for $60 \mathrm{~min}$, followed by inactivation of the enzyme at $95^{\circ} \mathrm{C}$ for $5 \mathrm{~min}$.

PCR amplification with different gene specific primers (22 pairs of primers) was performed to amplify the product containing the full length of all genes of influenza. Twenty-five micro liters PCR-mix contained $1 \times$ Platinum Taq buffer (Invitrogen), $200 \mu \mathrm{M}$ dNTP, $2.5 \mathrm{mM} \mathrm{MgCl2,}$ $240 \mathrm{nM}$ each of $\mathrm{Fw}$ primer and Rw primer, 1 U Platinum Taq DNA Polymerase (Invitrogen) and $3 \mu \mathrm{l}$ cDNA. Reactions were placed in a thermal cycler at $95^{\circ} \mathrm{C}$ for $2 \mathrm{~min}$, then cycled 35 times between $95^{\circ} \mathrm{C} 20 \mathrm{sec}$, annealing at $58^{\circ} \mathrm{C}$ for $60 \mathrm{sec}$ and elongation at $72^{\circ} \mathrm{C}$ for $90 \mathrm{sec}$ and were finally kept at $8^{\circ} \mathrm{C}$ until later use.

\section{Phylogenetic and Sequence Analysis}

Sequences of purified PCR products were determined using gene specific primers and BigDye Terminator version 3.1 chemistry (Applied Biosystems, Foster City, CA), according to the manufacturer's instructions. Reactions were run on ABI310 10 DNA analyzer (Applied Biosystems). Sequencing was performed at least twice in each direction. After sequencing, assembly of sequences, removal of low quality sequence data, nucleotide sequence translation into protein sequence, additional multiple sequence alignments and processing were performed with the Bioedit software version 7.0.4.1 with an engine-based on the Clustal W algorithm. The phylogenetic analysis, based on complete gene nucleotide sequences, were conducted using Molecular Evolutionary Genetics Analysis (MEGA, version 5.0) software employing neighbor-joining tree inference analysis with the Tamura-Nei $\gamma$-model, with 1000 bootstrap replications to assign confidence levels to branches (Saitou, 1987; Tamura, 2004; Tamura, 2011).

\section{Sequences Obtained from GenBank}

The 29 previously described and selected by BLAST ( $>90 \%$ amino acid sequence similarity) sequences of influenza viruses were used for comparison with avian influenza strain isolated in Kazakhstan (Table 1). The choice of strains was carried out according to the following criteria: representatives of different geographical regions; various periods of isolation; and representatives of which are within the average statistical monophyletic groups of strains on the phylogenetic tree. Such strains selection allows to simply assessing the presence or absence of reassortment in influenza virus.

\section{Nucleotide Sequence Accession Numbers}

The nucleotide sequences for all viral segments of strain A/mute swan/Aktau/1460/06 analyzed in this study are available from GenBank under accession numbers from FJ434373 to FJ434380.

\section{Results and Discussion}

29 sequences of influenza viruses previously described and selected by BLAST $(>90 \%$ amino acid sequence similarity) were used for comparison with avian influenza strain isolated in Kazakhstan (Table 1). It is interesting that the program had selected various strains of avian influenza for different genes. Thus, the internal virus segments excluding PB2 gene formed a close group with viruses isolated in Yangzhou, Jiang $\mathrm{Xi}$ and Astrakhan with high degree of identity (Table 1). Genes PB2 and HA formed a separate branch with strains isolated in Mongolia and Guangdong. The NA gene was distinctly related to the isolates from Korea (Table 1). 
Table 1. Influenza A Viruses with Highest Nucleotide Sequence Identity to H5N1 Influenza Virus (A/Mute Swan/Aktau/1460/06) as Determined by BLAST Search in the NCBI.

\begin{tabular}{|c|c|l|c|c|}
\hline Gene & $\begin{array}{c}\text { Identity } \\
\mathbf{( \% )}\end{array}$ & \multicolumn{1}{|c|}{ Virus designation } & Subtype & $\begin{array}{c}\text { GenBank } \\
\text { accession no }\end{array}$ \\
\hline PB2 & $98 \%$ & duck/Mongolia/54/2001 & H5N2 & AB301913 \\
& $95 \%$ & duck/Guangdong/07/2000 & H5N1 & AY585509 \\
\hline PB1 & $96 \%$ & duck//iang Xi/1286/2005 & H5N2 & EF597440 \\
& $95 \%$ & duck/Mongolia/54/2001 & H5N2 & AB302086 \\
& $94 \%$ & duck/Yangzhou/02/2005 & H8N4 & EF061124 \\
& $94 \%$ & gull/Astrakhan/1846/1998 & H13N6 & GU052232 \\
\hline PA & $96 \%$ & duck/Mongolia/54/2001 & H5N2 & AB301914 \\
& $96 \%$ & duck/Yangzhou/02/2005 & H8N4 & EF061120 \\
& $95 \%$ & duck/Jiang Xi/1286/2005 & H5N2 & EF597405 \\
& $94 \%$ & duck/Guangdong/07/2000 & H5N1 & AY585467 \\
\hline HA & $97 \%$ & duck/Mongolia/54/2001 & H5N2 & AB301914 \\
& $96 \%$ & duck/Jiang Xi/1286/2005 & H5N2 & EF597258 \\
& $90 \%$ & duck/Guangdong/07/2000 & H5N1 & AY585373 \\
\hline NP & $97 \%$ & duck/Mongolia/54/2001 & H5N2 & AB301914 \\
& $96 \%$ & duck/Yangzhou/02/2005 & H8N4 & EF061123 \\
& $96 \%$ & gull/Astrakhan/1846/1998 & H13N6 & GU052230 \\
& $94 \%$ & duck/Guangdong/07/2000 & H5N1 & AY585425 \\
\hline NA & $97 \%$ & duck/Korea/S17/03 & H6N1 & AY862645 \\
& $93 \%$ & duck/Guangdong/07/2000 & H5N1 & AY585404 \\
\hline M & $99 \%$ & duck/Mongolia/54/2001 & H5N2 & AB301914 \\
& $99 \%$ & gull/Astrakhan/1846/1998 & H13N6 & GU052230 \\
& $98 \%$ & duck/Yangzhou/02/2005 & H8N4 & EF061125 \\
& $98 \%$ & duck//iang Xi/1286/2005 & H5N2 & EF597279 \\
\hline NS & $98 \%$ & gull/Astrakhan/1846/1998 & H13N6 & GU052231 \\
& $97 \%$ & duck/Yangzhou/02/2005 & H8N4 & EF061119 \\
& $96 \%$ & duck/Mongolia/54/2001 & H5N2 & AB301917 \\
& $96 \%$ & duck/Guangdong/07/2000 & H5N1 & AY585446 \\
\hline
\end{tabular}

The sequences of all eight gene segments of avian influenza isolate A/mute swan/Aktau/1460/06 were determined and were compared to other sequences that were available in GenBank (Fig. 1). A phylogenetic analysis of eight gene segments showed that the Kazakhstanian isolate was of avian origin and, in general, showed the highest amino acid sequence similarity to avian influenza gene pool of the western Pacific migratory flyway with viruses from China, Korea, Japan, Mongolia and Siberia. However, it was shown that there has also been "mixing" attitudinally through overlapping migratory flyways in the region of Caspian Sea. It was interesting that sequences of PB2, HA and NA genes were formed from some different evolutionary groups. 


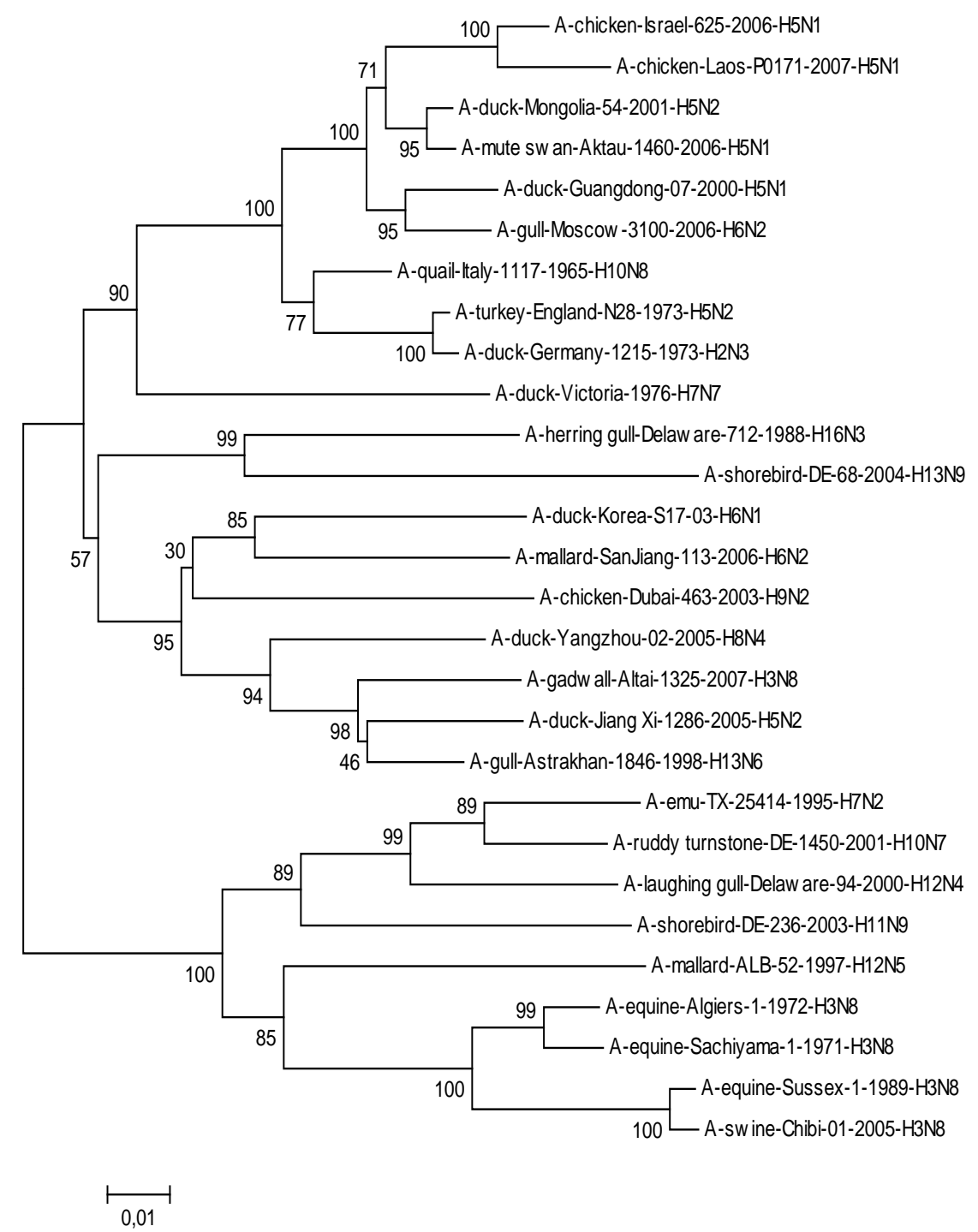

PB2 


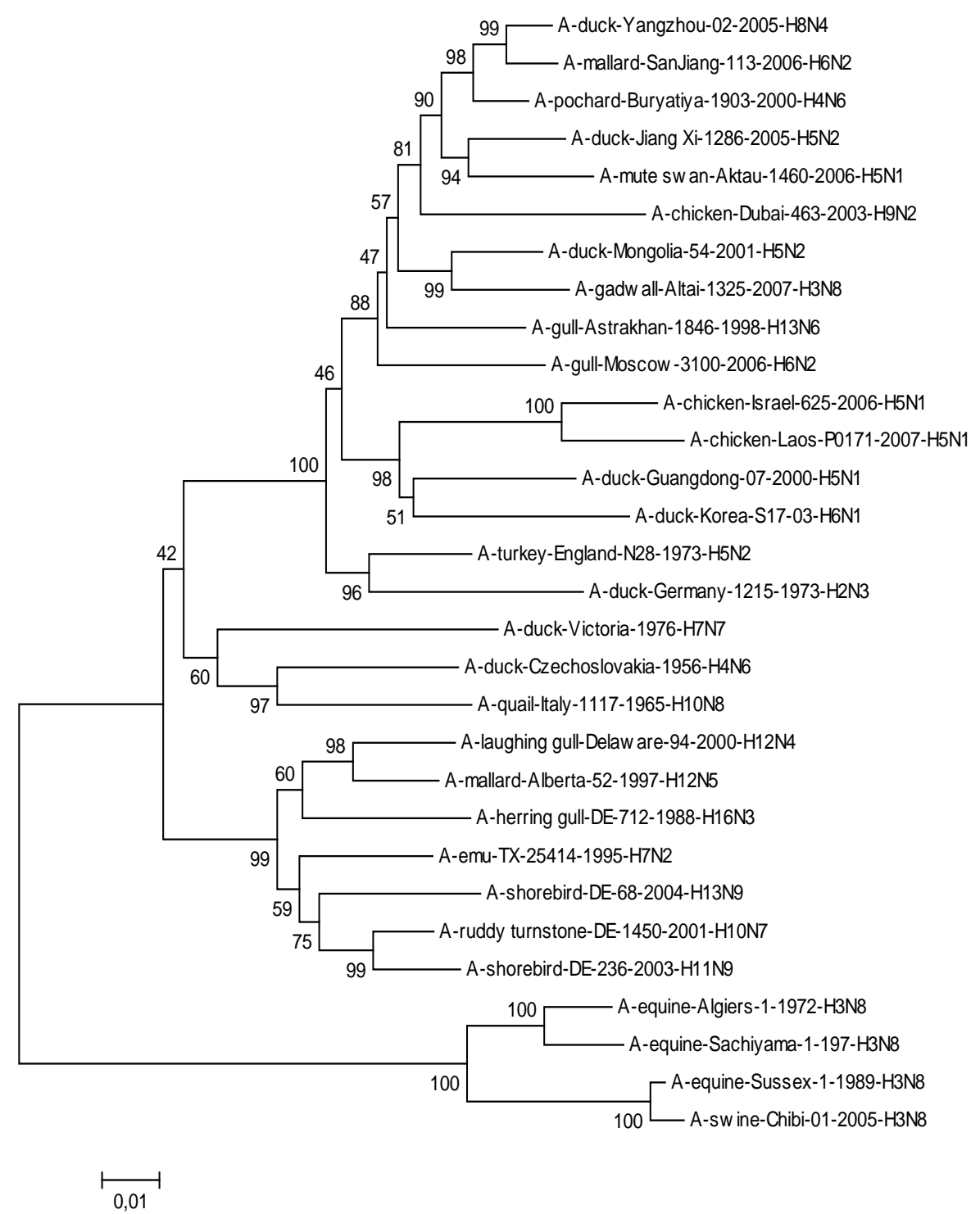

PB1 


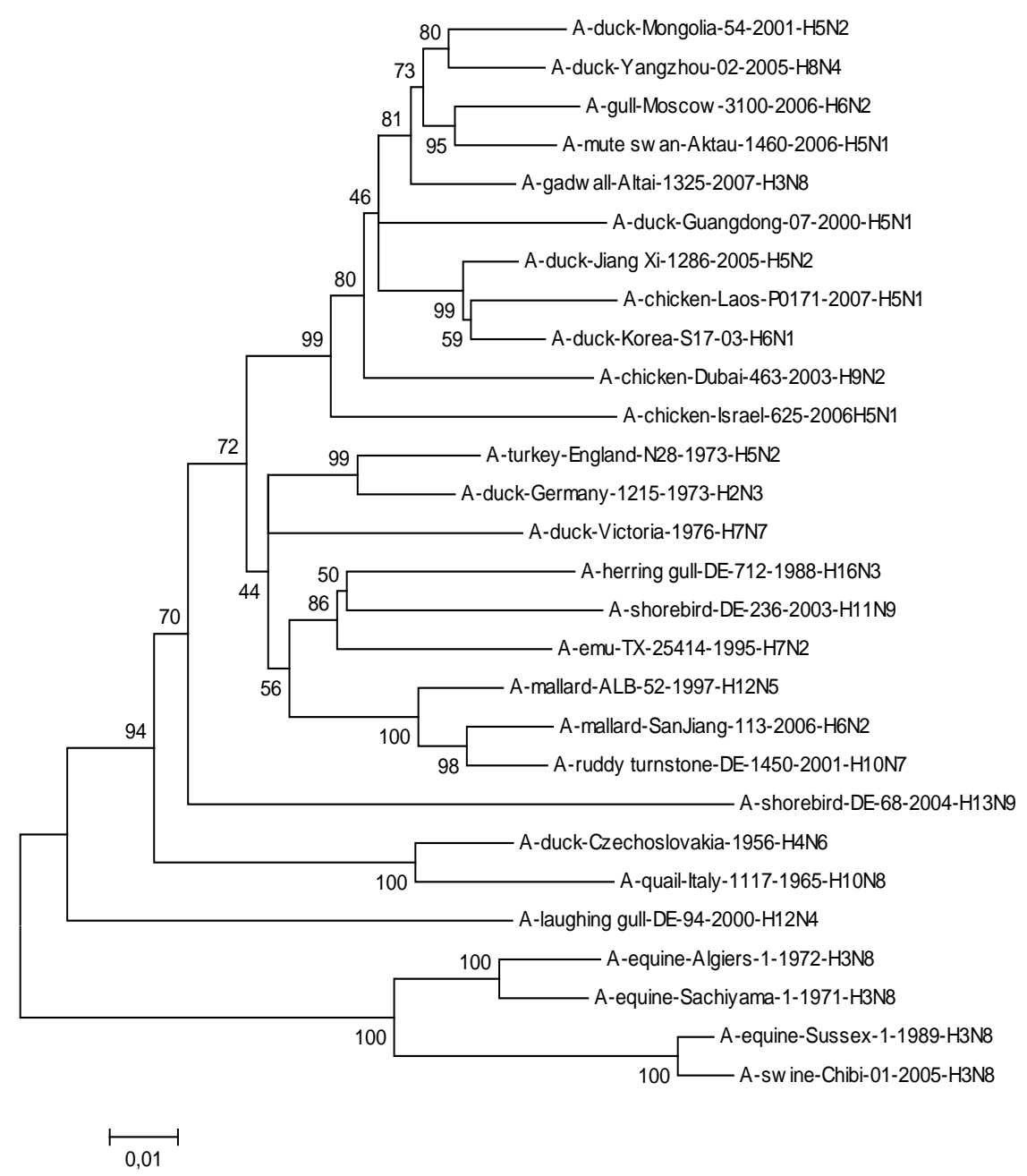

PA 


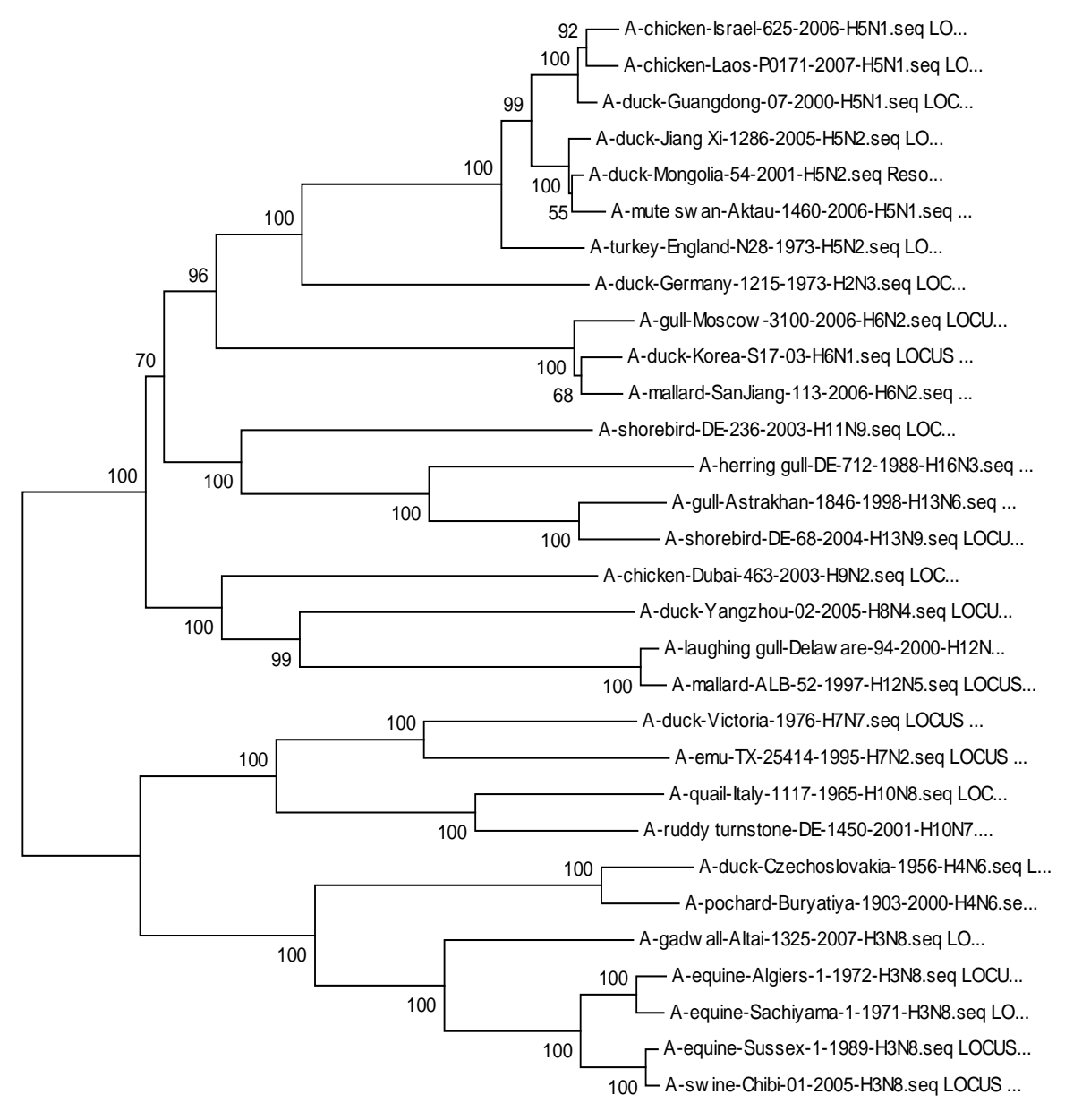

0,1

HA 


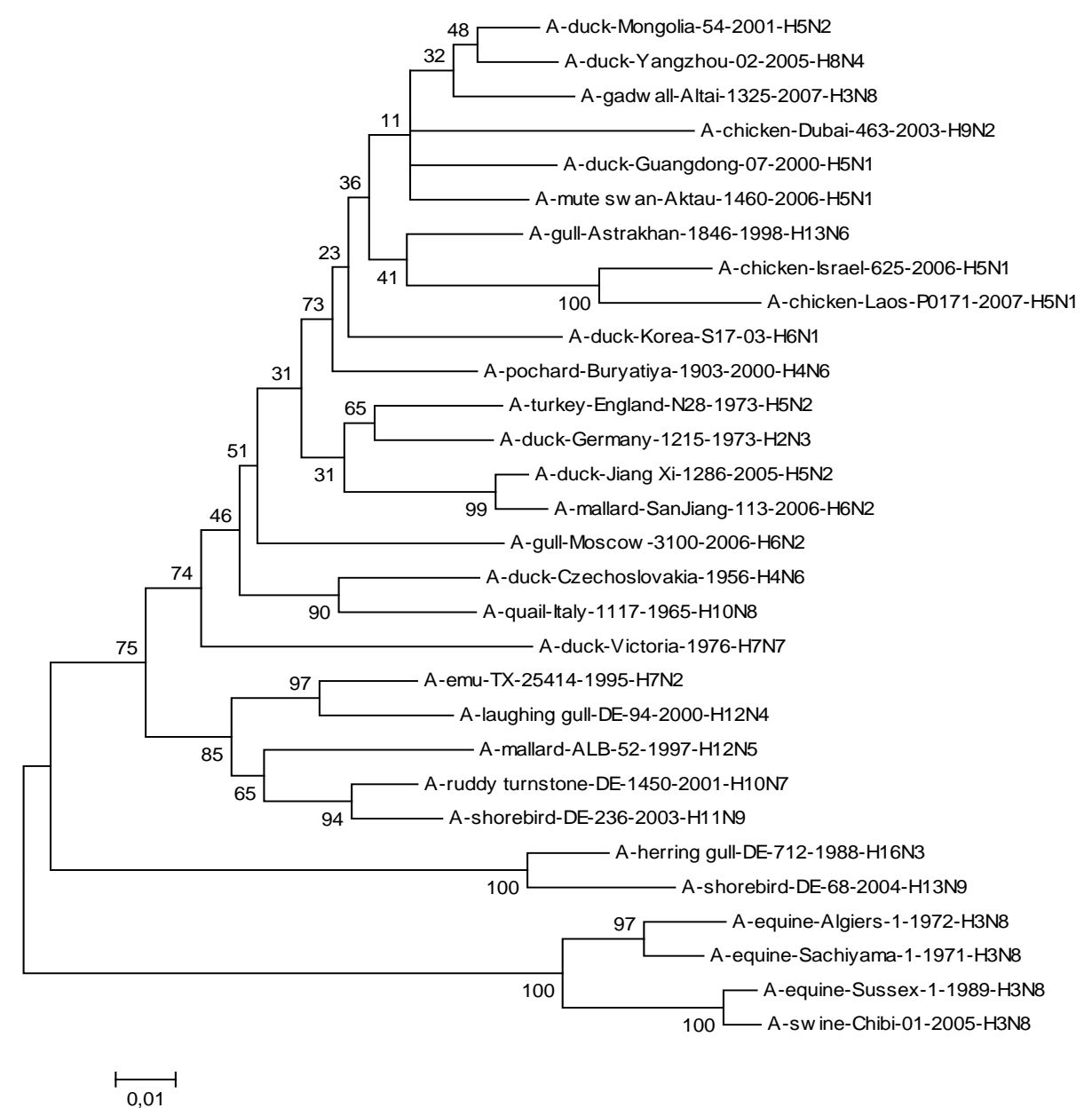




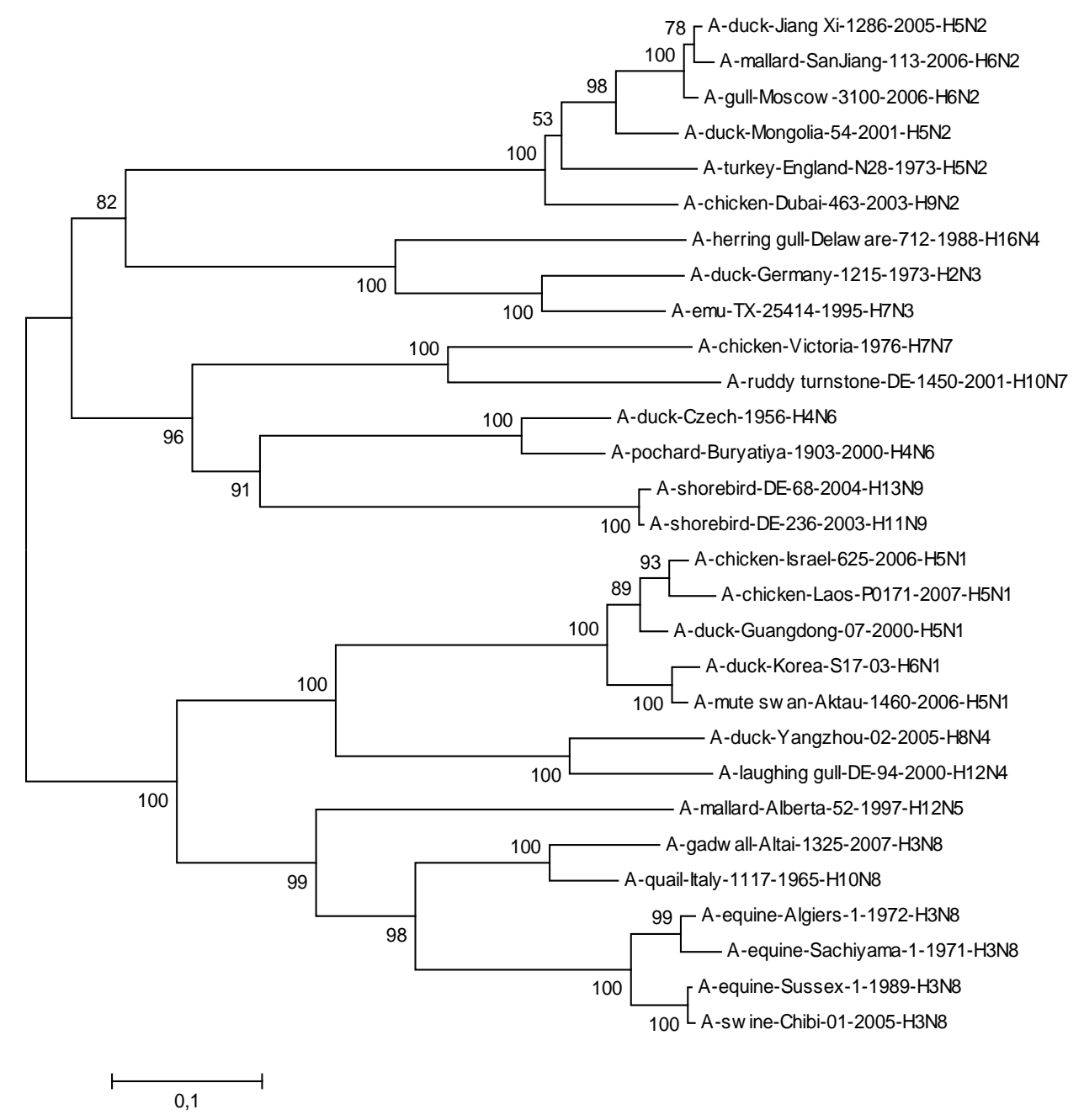

NA 


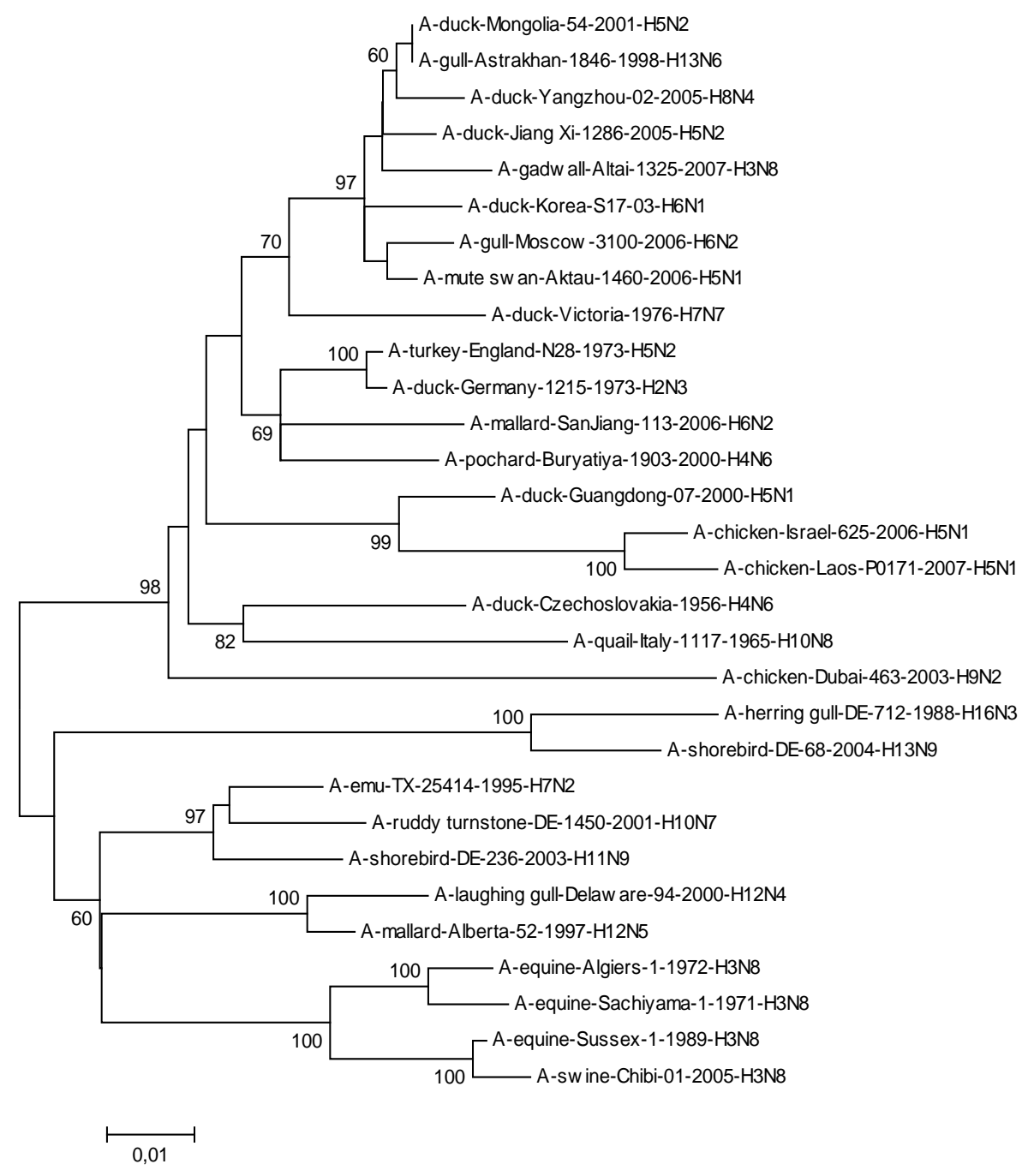




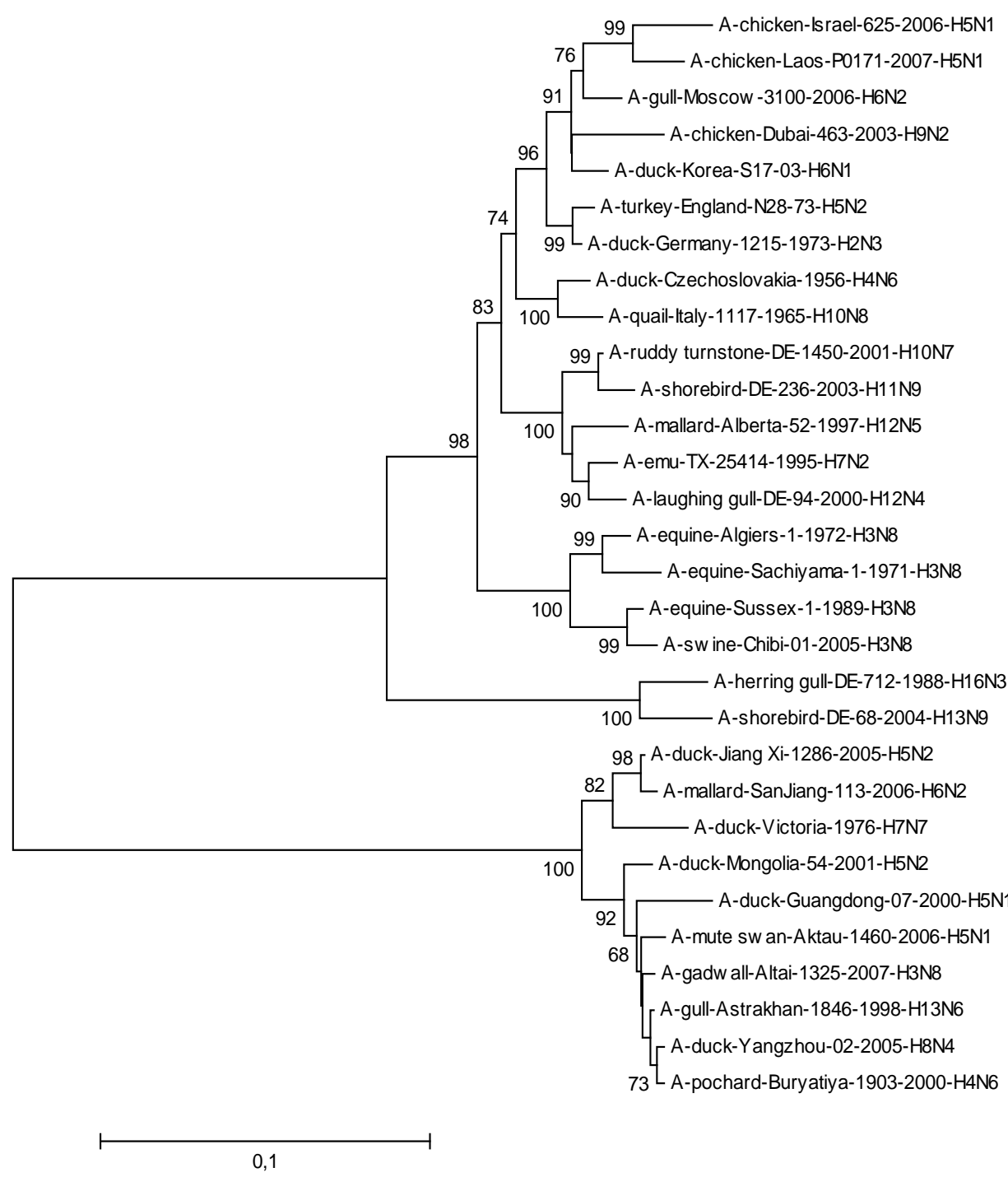

Figure 1 - Phylogenetic Trees of Virus Genes Isolated from Mute Swan in Kazakhstan. Trees were Generated by Using Neighbor-Joining Analysis. The Evolutionary Distances Were Computed Using the Tamura-Nei Method and are in the Units of the Number of Base Substitutions per Site. The Percentage of Replicate Trees in which the Associated Taxa Clustered Together in the Bootstrap Test (1000 Replicates) are Shown Next to the Branches. Analysis was Based on Total Nucleotides 1048 bp of the PB2 Gene, 1194 bp of the PB1 Gene, 1219 bp of the PA Gene, 1559 bp of the HA Gene, 429 bp of the NP Gene, $560 \mathrm{bp}$ of the NA Gene, $961 \mathrm{bp}$ of the M Gene and $800 \mathrm{bp}$ of the NS Gene. All Positions Containing Gaps and Missing Data were Eliminated from the Dataset (Complete Deletion Option). Phylogenetic Analyses were Conducted in MEGA4 [4]. The Mute Swan Genes are Indicated in Box.

Therefore we decided to use the FluGenome, an online set of tools software, for the classification of different lineages and genotypes of influenza virus $\mathrm{A} /$ mute
swan/Aktau/1460/06 (H5N1) that arose by divergence between different influenza strains cocirculated in the same territory (Lu, 2007). 
It was shown that influenza virus $\mathrm{A} /$ mute swan/Aktau/1460/06 (H5N1) had the genotype $[\mathrm{K}, \mathrm{G}, \mathrm{D}, 5 \mathrm{H}, \mathrm{F}, 1 \mathrm{H}, \mathrm{F}, 2 \mathrm{~A}]$ and was natural reassortant from different lineages of influenza evolution. The possible derivation of this strain is summarized in Fig. 2. By analysis data of genotyping it has been detected that this new unique genotype arose from reassortment events between three different groups.

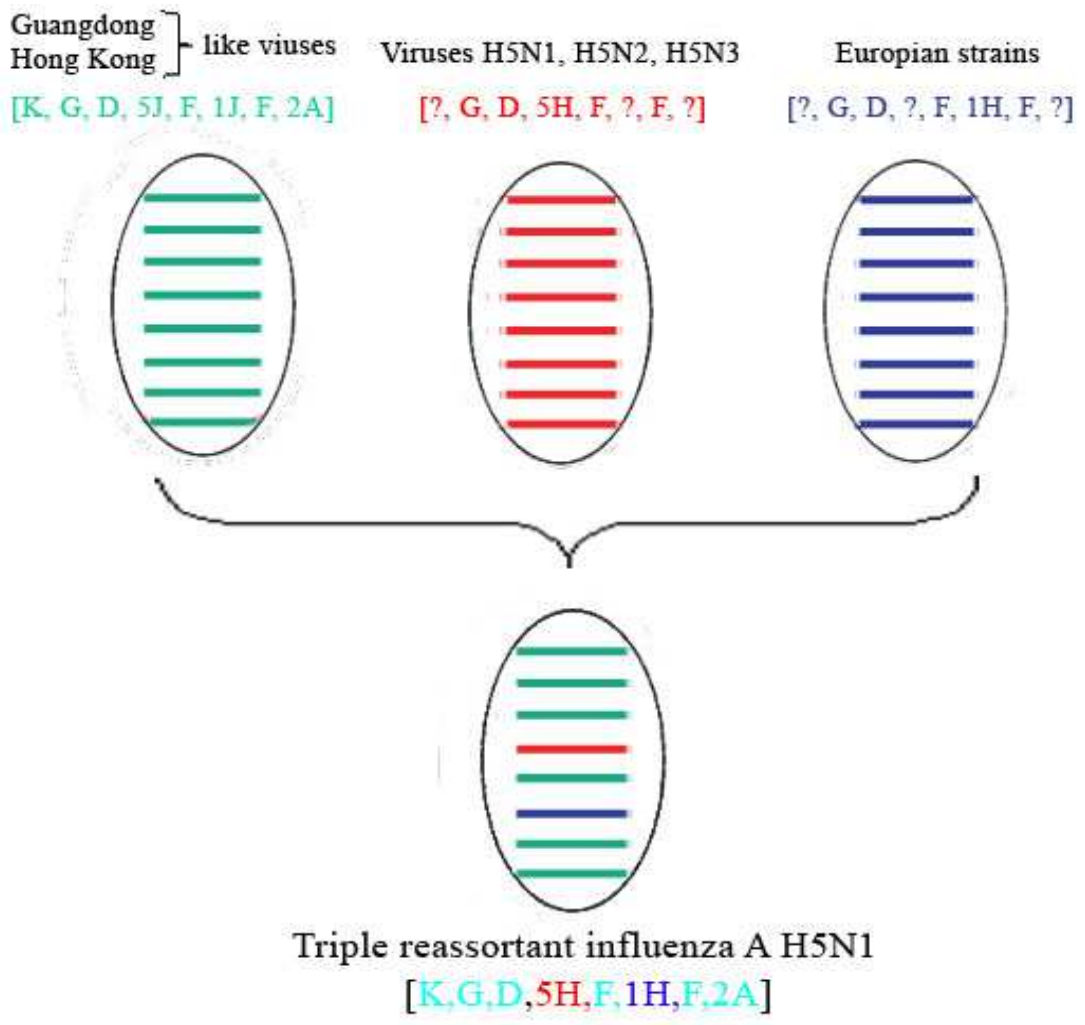

Figure 2 - FluGenome Detects the Genesis of Triple Reassortant Influenza A Virus Isolated in Kazakhstan.

The origin of the strain $\mathrm{A} /$ mute swan/Aktau/1460/06 is unclear. The authors suggest that this H5N1 reassortant virus acquired its PB2, PB1, PA, NP, M and NS gene segments from viruses isolated in China and circulating from 1992 to 2005, whose genotype were [K,G,D,5J,F,1J,F,2A]. These strains have subtypes H5N1, H5N2 and H3N8. The HA genes are descended from A/duck/Mongolia/54/2001 (AB241614), A/duck/Jiang Xi/6146/2003 (EF597255), and A/duck/Gui Yang/3799/2005-like viruses (EF597261). These viruses belong to H5N1, H5N2 and H5N3 subtypes. The remaining NA gene segment might have been originated from a group of viruses which predominantly were isolated in Europe between 1999 and 2005 and have H7N1, H1N1, H6N1 and H11N1 subtypes.
Here, the authors report the results which indicate that the new virus is a triple reassortant, as a result of reassortment event between two geographical lineages. The virus had acquired six inner gene segments from one group, HA gene from another group and NA gene from a third group. This fact confirms that genetically different viruses can cocirculate at the same territory, as previously suggested (Fasina, 2007; Gaidet, 2007; Pittman, 2008).

The present results indicate that a new H5N1 virus with unique genotype was found in mute swan. The similarity of the inner and HA genes with the same of China isolates indicate that they had some connection with Asian lineage of evolution. The similarity of PB2 and NA genes with 
one of the strains isolated in Europe indicates that the strain $\mathrm{A}$ /mute swan/Aktau/1460/06 had a relationship with European lineage of evolution.

\section{Conclusion}

This study demonstrates the dynamic nature of the influenza virus genes pool in Eurasia with continuing gene exchanges between the eastern and western parts of the continent. The findings suggest that the H5N1-like virus were likely derived directly from viruses resident in migratory birds. The failure to identify the source for all gene segments of A/mute swan/Aktau/1460/06 virus and its variant highlights the need for continuance of surveillance in both migratory and domestic populations of birds in large regions. Such surveillance is crucial for effective pandemic influenza preparedness.

\section{Acknowledgments}

The study was supported by USDA-ISTC partner project (K-747p, Institute of Microbiology and Virology funding, and USDA CRIS (6612-32000-038-00 D)) and with a grant of the Ministry of Science and Education, Republic of Kazakhstan, 0106 РК00581.

The authors express their deep appreciation to Sayatov M. and staff of the laboratory ecology of viruses for the opportunity to work with the virus.

\section{References}

Alexander, D. J. (2007). "Summary of Avian Influenza Activity in Europe, Asia, Africa, and Australasia, 2002-2006," Avian Diseases, 51(1 Suppl) 161-166.

Bogoyavlenskiy, A., Berezin, V., Korotetskiy, I. et al. (2011). 'Genetic Characterization of H4, H5 and H13 Type Avian Influenza Viruses Isolated from Wild Birdsa in Kazakhstan,' Influenza and Other Respiratory Viruses, Vol. 5, 60-62.

Chervyakova, O. V., Strochkov, V. M., Sultankulova, K. T., Sandybayev, N. T., Zaitsev, V. L. \& Mamadaliyev, S. M. (2011).
"Molecular and Genetic analysis of NS Gene from High Pathogenic Strains of the Avian Influenza (H5N1) Virus Isolated in Kazakhstan," Gene, 476 (1-2) 15-9.

Cox, N. J. \& Subbarao, K. (2000). “Global Epidemiology of Influenza: Past and Present," Annual Review of Medicine, 51 407-421.

European Union Council Directive 92/40/EEC of 19 May 1992. "Introducing Community Measures for the Control of Avian Influenza," Official Journal L 167, 22/06/1992. 0001-0016.

Fasina, F. O., Meseko, A. C., Joannis, T. M., Shittu, A. I., Ularamu, H. G., Egbuji, N. A., Sulaiman, L. K. \& Onyekonwu, N. O. (2007). "Control Versus No Control: Options for Avian Influenza H5N1 in Nigeria," Zoonoses Public Health, Vol. 54(5) 173-176.

Forrest, H. L. \& Webster, R. G. (2010). "Perspectives on Influenza Evolution and the Role of Research, " Animal Health Research Review, 11(1) 3-18.

Gaidet, N., Dodman, T., Caron, A., Balança, G., Desvaux, S., Goutard, F., Cattoli, G., Lamarque, F., Hagemeijer, W. \& Monicat, F. (2007). "Avian Influenza Viruses in Water Birds, Africa," Emerging Infectious Diseases, Vol. 13(4) 626-629.

Horimoto, T. \& Kawaoka, Y. (2001). "Pandemic Threat Posed by Avian Influenza A Viruses," Clinical Microbiology Reveiws, 14(1) 129-49.

Horimoto, T. \& Kawaoka, Y. (2005). "Influenza: Lessons from Past Pandemics, Warnings from Current Incidents," Nature Reviews Microbiology, 3 591-600.

Kaverin, N. (2010). "Postreassortment Amino Acid Substitutions in Influenza A Viruses," Future Microbiology, 5(5) 705-15.

Kydyrbayev, Z. K., Tabynov, K. K., Ryskeldynova, S. Zh., Mamadaliyev, S. M. \& Khairullin B. M. (2010). "Immunogenicity of the Inactivated Oil Emulsion Influenza $\mathrm{A}$ (H5N1) Vaccine in Chickens," Agriculture and Biology Journal of North America, 1(3) 201-207. 
Lei, F. \& Shi, W. (2011). "Prospective of Genomics in Revealing Transmission, Reassortment and Evolution of WildlifeBorne Avian Influenza A (H5N1) Viruses," Current Genomics, 12(7) 466-74.

Lu, G., Rowley, T., Garten, R. \& Donis, R. 0. (2007). "FluGenome: A Web Tool for Genotyping Influenza A Virus," Nucleic Acids Research, Vol 35, W275-W279.

Pittman, M. \& Laddomada A. (2008). "Legislation for the Control of Avian Influenza in the European Union," Zoonoses and Public Health, Vol. 55(1) 29-36.

Saitou, N. \& Nei, M. (1987). "The NeighborJoining Method: A New Method for Reconstructing Phylogenetic Trees," Molecular Biology and Evolution, 4 406425.

Salzberg, S. L., Kingsford, C., Cattoli, G., Spiro, D. J., Janies, D. A., Aly, M. M., Brown, I. H., Couacy-Hymann, E., De Mia, G. M., Dung, D. H., Guercio, A., Joannis, T., Ali, A. S. M., Osmani, A., Padalino, I., Saad, N. D., Savić, V., Sengamalay, N. A., Yingst, S. L., Zaborsky, J., Zorman-Rojs, O., Ghedin, E. \& Capua, I. (2007). "Genome Analysis Linking Recent European and African Influenza (H5N1) Viruses," Emerging Infectious Diseases, Vol. 13(5) 713-718.

Sayatov, M. K. h., Kydyrmanov, A., Asanova, S. et al. (2007). 'Influenza A Virus Surveillance in Wild Birds in Northern and Eastern Caspian in 2002-2006,' In: International Conference Materials "Preparedness to the Influenza Pandemic An International Outlook"., SaintPetersburg, Russia, 2007, 79-80.

Tabynov, K. K., Mambetaliyev, M. A., Mamadaliyev, S. M., Bulatov, Ye. A. \& Kopochenya, A. A. (2008). 'Determination of the Intravenous Pathogenicity Index of the Influenza A Virus Isolated in Kazakhstan in 2005-2006,' Biotechnology in the republic of Kazakhstan: problems and trends of innovation development, $2008 \mathrm{P}$. 209-211.

Tamura, K., Nei, M. \& Kumar, S. (2004). "Prospects for Inferring Very Large
Phylogenies by Using the Neighbor-Joining Method," Proceeding of the National Academy of Sciences of the United States of America, 101:11030-11035.

Tamura, K., Peterson, D., Peterson, N., Stecher, G., Nei, M. \& Kumar, S. (2011). "MEGA5: Molecular Evolutionary Genetics Analysis Using Maximum Likelihood, Evolutionary Distance, and Maximum Parsimony Methods," Molecular Biology and Evolution, 28(10) 2731-2739.

Webster, R. G. \& Hulse, D. J. (2004). "Microbial Adaptation and Change: Avian Influenza," Revue Scientifique et technique, 23(2) 453-65. 